Bangladesh J. Bot. 49(4): 1037-1044, 2020 (December)

\title{
EFFECTS OF SUPERFINE GRINDING ON MICROMERITIC PROPERTIES OF EUCOMMIA ULMOIDES OLIV. LEAVES
}

\author{
Peiqi Zhang ${ }^{1}$, Shanshan TiE ${ }^{1}$, Mengpei Liu ${ }^{1}$ and Wei Zong* ${ }^{1}$ \\ ${ }^{1}$ Key Laboratory of Cold Chain Food Quality and Safety Control, Zhengzhou \\ University of Light Industry, Zhengzhou, Henan 450002, China
}

Keywords: Eucommia ulmoides, Superfine grinding, Micromeritic properties

\begin{abstract}
Effects of regular grinding and superfine grinding on the micromeritic properties of Eucommia ulmoides leaves were investigated. Coarse powder $1(5732 \mathrm{~nm}), 2(4784.67 \mathrm{~nm}), 3(4133.67 \mathrm{~nm}), 4(2119 \mathrm{~nm})$ were prepared by regular grinding. Superfine powder $5(1310.67 \mathrm{~nm})$ was prepared by superfine grinding, all the particle sizes presented normal distribution. Results showed that Eucommia ulmoides leaf powders have smaller size, greater bulk density and smaller angle of repose. The water solubility index values, water holding capacity value and oil binding capacity value were significantly improved as the size decreases. Furthermore, biological microscopy revealed the surface morphology of five powders. FT-IR analysis showed the nature of Eucommia ulmoides leaves unchanged. These results showed that the physicochemical and functional properties of Eucommia ulmoides leaves can be improved by superfine grinding, which would be more suitable for the development of functional compounds than native Eucommia ulmoides leaves.
\end{abstract}

\section{Introduction}

Eucommia ulmoides Oliv. is a traditional Chinese medicine, it can be used as an antihypertensive, protects muscle, bone and liver and kidney herb. It has also been processed as tea, popular drink in China which is known as health food (Xu et al. 2010, Fujikawa et al. 2012, Sugawaa et al. 2012, Hosoo et al. 2015). Eucommia ulmoides leaves contain the active ingredients: iridoid glycosides, geniposidic acid, chlorogenic acid etc. (Chen et al. 2010, Zhang et al. 2013). Eucommia ulmoides leaves have also been reported to have antioxidant, anti-mutagenic and anti-mutagenic effects (Fujikawa et al. 2010, Lin et al. 2011). Its extraction is commonly used to treat hypertension and diabetes, also exhibits effects such as anti-fatty liver, anti-hypercholes- terolemia, anti-oxidative stress and anti-obesity (Zhang et al. 2007, Choi et al. 2008, Hirata et al. 2011). Its extract may be an important source of natural antioxidants (Xu et al. 2010). These indicate that Eucommia ulmoides leaves have great potential to be used as Chinese medicine raw materials.

Superfine grinding is a new process technique which has great potential in producing powder foods (Zhang et al. 2014). It can reduce the particle size of food ingredients to reach the range from $1 \mathrm{~nm}$ to $100 \mu \mathrm{m}$ (Xiao et al. 2017). Meanwhile, superfine grinding technology is a pure physical process to get product, with decreasing particle size of product. In grinding process, the morphological properties of materials have great changes, can bring out extraordinary characteristics relative to crude particles, for example, possessing good surface properties, solubility, water holding capacity, oil holding capacity and solubility (Zhao et al. 2010, Hu et al. 2012, Phata et al. 2015). Because of these outstanding advantages, superfine powders can be used in many fields such as food, Chinese patent drug and mineral (Zhao et al. 2015). These advantage properties not shown by coarse powder. It is usually effective to grind the biomaterials into

*Author for correspondence: <Zongwei1965@126.com>. ${ }^{1}$ Collaborative Innovation Center of Food Production and Safety, Zhengzhou 450002, China. 
superfine powders for efficient extraction (Chen et al. 2014). Zhu et al. (2015) found powder particle size distribution of superfine grinding was close to a Gaussian distribution, and has relatively higher capacity in water retention, swelling and nitrite ion absorption. Zhong et al. (2016) found that the superfine grinding process would not influence chemical composition polyphenols and flavonoids and can improve the bioavailability of pomegranate peel. However, the effect of superfine grinding process on micromeritic properties of Eucommia ulmoides leaves has not been reported.

The objective of the work was to study how the micromeritic properties of Eucommia ulmoides leaf powder change during superfine grinding. In this study, Eucommia ulmoides leaf powders with different size were obtained and the micromeritic and physical-chemical properties were compared.

\section{Materials and Methods}

The dried Eucommia ulmoides Oliv. leaves were obtained from Shandong Beloeucommia Biological Engineering Co., LTD. Sunflower oil was bought from local market. Methanol and alcohol were purchased from Huafeng chemical reagent factory (Henan, China), and both solvents were of Analytical reagent. The coarse particles were grinded by a disc-mill to get four coarse powder 1 ( $\leq 100$ mesh), 2 (100 $<\mathrm{d} \leq 200 \mathrm{mesh}), 3$ (200 $<\mathrm{d} \leq 300 \mathrm{mesh})$ and 4 ( $\geq 300 \mathrm{mesh})$. The superfine powder 5 was obtained in a WFJ-15 type micronizer (Yongchang Medicine Machinery Co., Ltd., China).

Samples for analysis were prepared by diluting $1 \mathrm{~g}$ coarse powders and superfine powder solution in a certain volume of ethanol. These were filled in some square plastic cuvette with between 1.0 and $1.5 \mathrm{ml}$ and measured on Malvern Zetasizer Nano- ZS90.

The morphology of samples was determined by biological microscope. The bulk density $(\mathrm{g} / \mathrm{ml})$ was measured by the method described by Chen et al. (2015). Angle of repose was determined by the method of Liu et al. (2015). Water solubility index (WSI) was analysed by the method of Vladi'c et al. (2016).

The Eucommia ulmoides leaf powders were prepared by potassium bromide pellet method for Fourier transform infrared spectroscopy (FTIR) detection (Zhao et al. 2013). Each spectrum was collected with a resolution of $4 / \mathrm{cm}$ with 32 scans and a $2 / \mathrm{cm}$ interval from 4000 to $400 / \mathrm{cm}$ region.

SPSS 16.0 and Origin 7.0 were used to analyse data. All data are expressed as means $\pm \mathrm{Sd}$ from triplicate samples. Significance was determined using the $\mathrm{p}$ value generated through $\mathrm{t}$ test.

\section{Results and Discussion}

Particle is an important quality for food powder (Sun et al. 2016). The effect of superfine grinding and regular grinding on the particle sizes of the Eucommia ulmoides leaf powders is presented in Fig. 1 and Table 1.

Fig. 1 showed that all the particle sizes presented normal distribution, thus the mean particle size could be chosen as the sizes of Eucommia ulmoides leaf powders (Table 1). The particle size distribution of the superfine powder 5 was narrower and more uniform than the coarse powders. According to the results, the mean particle size of superfine powder E was $1310.67 \mathrm{~nm}$, the mean particle size of the coarse powder 1, 2, 3, 4 were 5732, 4784.67, 4133.67 and $2119 \mathrm{~nm}$, respectively. Meanwhile, statistical analysis results showed that the mean particle sizes of different sample hve significant difference $(\mathrm{p}<0.05)$. 
Biological microscope was used to observe the changes in morphology and sizes after superfine grinding and regular grinding treatment. Fig. 2 showed that the cell structure of regular grinding was more complete compared with superfine grinding.

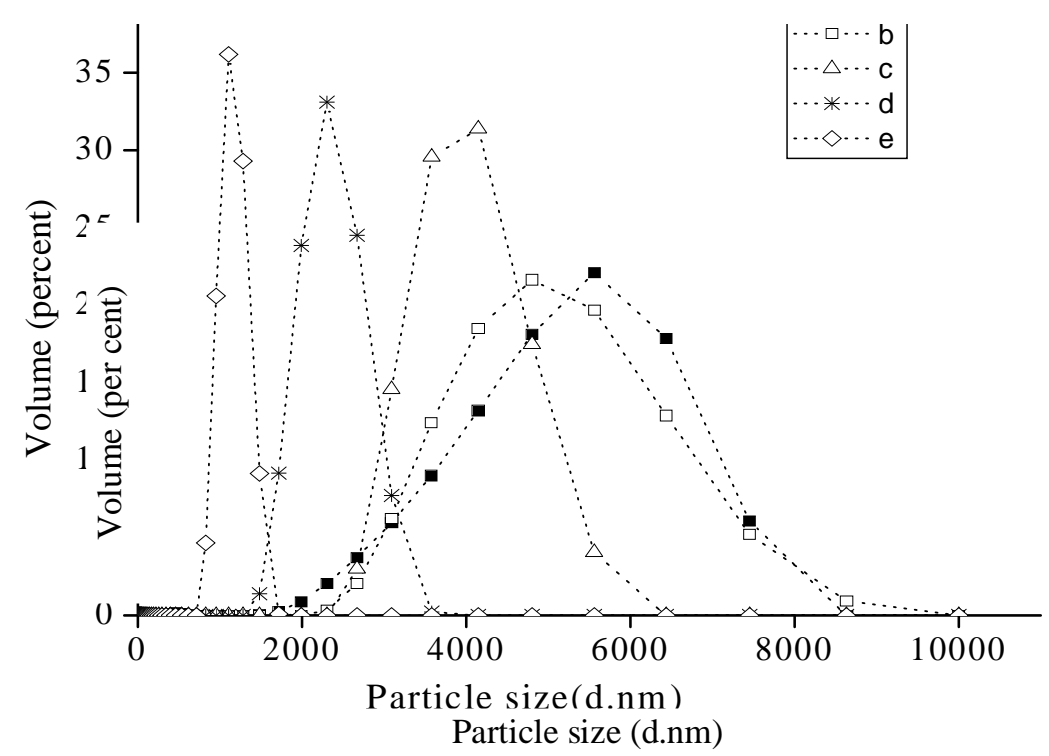

Fig. 1. The particle sizes distribution of the Eucommia ulmoides leaf powders. a, b, c, d for coarse powder 1, 2, 3, 4; e for superfine powder 5 .

Table 1. Characteristic index of different Eucommia ulmoides leaf powder.

\begin{tabular}{llccc}
\hline $\begin{array}{l}\text { Sample } \\
\text { No. }\end{array}$ & $\begin{array}{l}\text { Particle size } \\
(\mathrm{nm})\end{array}$ & $\begin{array}{c}\text { Bulk density } \\
(\mathrm{g} / \mathrm{ml})\end{array}$ & $\begin{array}{c}\text { Angle of repose } \\
\left({ }^{\circ} \mathrm{C}\right)\end{array}$ & $\begin{array}{c}\text { Water solubility index } \\
(\%)\end{array}$ \\
\hline 1 & $5732.00 \pm 232.71^{\mathrm{a}}$ & $0.2223 \pm 0.0156^{\mathrm{d}}$ & $41.57 \pm 0.34^{\mathrm{a}}$ & $21.12 \pm 0.74^{\mathrm{d}}$ \\
2 & $4784.67 \pm 194.19^{\mathrm{b}}$ & $0.2543 \pm 0.0143^{\mathrm{c}}$ & $40.84 \pm 0.07^{\mathrm{b}}$ & $22.84 \pm 0.52^{\mathrm{c}}$ \\
3 & $4133.67 \pm 74.08^{\mathrm{c}}$ & $0.2890 \pm 0.0130^{\mathrm{b}}$ & $40.51 \pm 0.18^{\mathrm{b}}$ & $25.49 \pm 0.66^{\mathrm{b}}$ \\
4 & $2119.00 \pm 130.28^{\mathrm{d}}$ & $0.3120 \pm 0.1104^{\mathrm{ab}}$ & $39.69 \pm 0.10^{\mathrm{c}}$ & $25.38 \pm 0.78^{\mathrm{b}}$ \\
5 & $1310.67 \pm 51.23^{\mathrm{e}}$ & $0.3237 \pm 0.1027^{\mathrm{a}}$ & $39.50 \pm 0.11^{\mathrm{c}}$ & $28.1 \pm 0.54^{\mathrm{a}}$ \\
\hline
\end{tabular}

Each value has three replicates; Different letters in the same column is significantly different $(\mathrm{p}<0.05)$.

The particle size of coarse powder 1 was relatively large, cell morphological structure was clearly observable, the particle sizes of other coarse powder gradually decreased, but the organizational structure of cells were still intact. The particle size of superfine powder 5 was significantly smaller and more uniform than coarse powder, there was only a small amount of cell gathering and most difficult to see the complete cells exist. Mechanical damage was a transformation from an ordered structure to a disordered one via the breakage of intermolecular bonds. Furthermore, it may impact on physical-chemical properties of powder (Zhao et al. 2010).

It is apparent from Table 1 that the bulk density of E. ulmoides leaf powders ranged from 0.2223 to $0.3237 \mathrm{~g} / \mathrm{ml}$, it increased with the decrease of particle size. The reason might be that 
superfine led to a probable decrease of the inter-particle voids of leaf powders, pore spaces between particles had a larger contact surface with the surroundings, so it can increase the value of bulk density. The results showed the the particle size has significant relevance on the bulk density ( $\mathrm{p}<0.05$ ). The leaf powders with higher bulk density was suitable for the preparation of solid drinks and capsule products (Zhao et al. 2009).
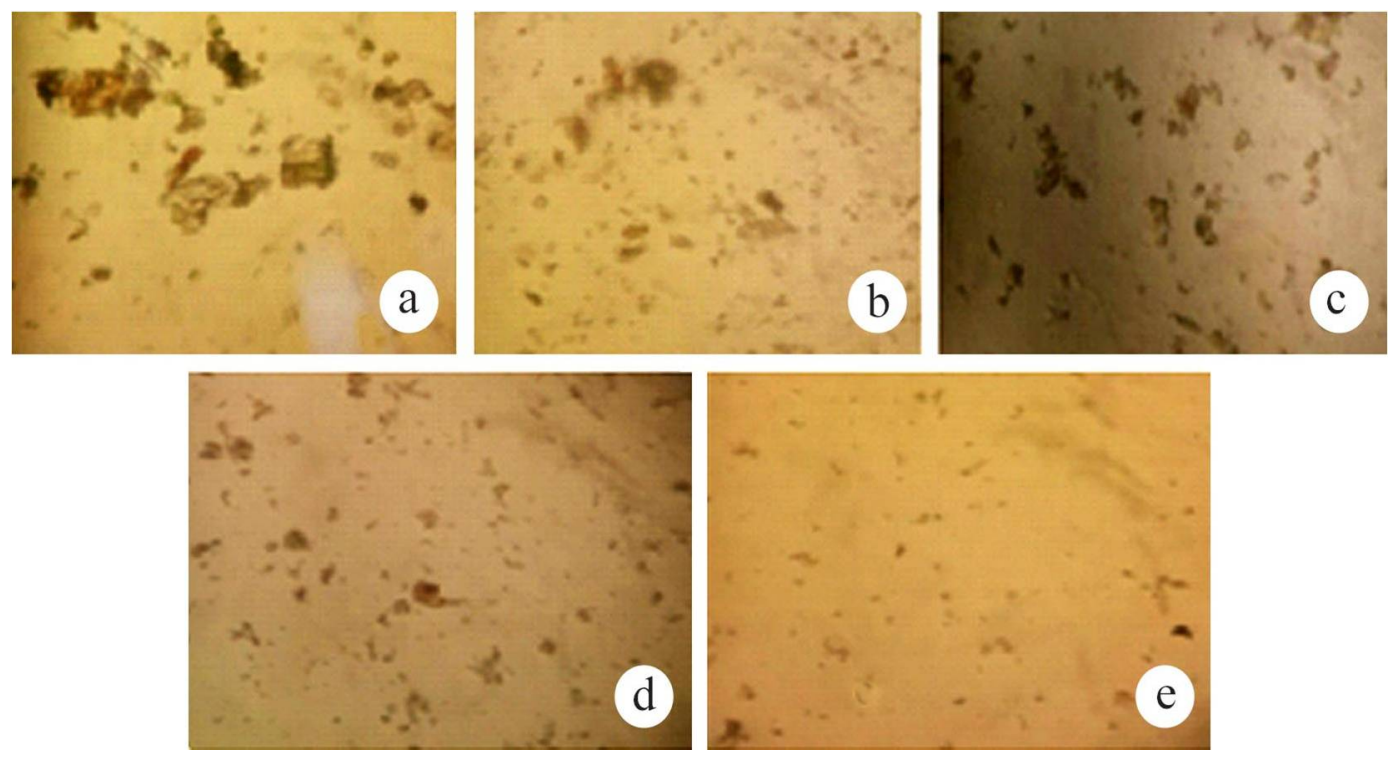

Fig. 2. The microstructure observation of Eucommia ulmoides leaf powders (400×). a, b, c, d for coarse powder 1, 2, 3, 4; e for superfine powder 5 .

The value of angle of repose is relevant in powder fluidity (Ming et al. 2015). The angle of repose values of different size of Eucommia ulmoides leaf particles is presented in Table 1, the angle of repose values ranged from $41.57^{\circ}$ (A) to $39.50^{\circ}$ (E). Angle of repose of different powder particles samples has significant differences $(\mathrm{p}<0.05)$. As angle of repose decreased, the fluidity of the powders can be improved (Ileleji et al. 2008).

Given either span or particle size distribution, small particles filled the voids of large particles and limited fluidity. As described above, superfine powders 5 had better flow behavior and the surface attachment of the powder would also be higher. The angle of repose of E. ulmoides leaf powders decreased with the reduction particle sizes. This might be due to the aggregates of particles between leaf powders (Chen et al. 2015).

As shown in Fig. 3a, the value of WHC increased as the particle sizes of Eucommia ulmoides leaf powders decreased. The WHC values powders $1-5$ ranged from 300.09 to $322.62 \%$. WHC of different powder particle samples has significant differences $(\mathrm{p}<0.05)$. The WHC value of powder 1 has the highest value among all samples. This is because that superfine grinding process can change the surface properties of powder by increasing the surface area and surface energy. Furthermore, superfine grinding process can expose the hydrophilic groups of cellulose and hemicelluloses of the E. ulmoides leaf powders. So it resulted in the increase of the value of WHC.

As Fig. $3 \mathrm{~b}$ showed, the oil binding capacity increased with the particle sizes of powders of $E$. ulmoides leaf decreased. More or less similar result was reported for apple pomace powder by 
Liang et al. (2016). The OBC values ranged from 140.67 (A) to $199.18 \%$ (E). OBC of different powder particles samples has significant differences $(p<0.05)$. The OBC value of powder 1 has the highest value among all samples. It might be due to cell wall of particles was broken in the superfine grinding process, exposed more lipophilic groups, so that the powder had relatively

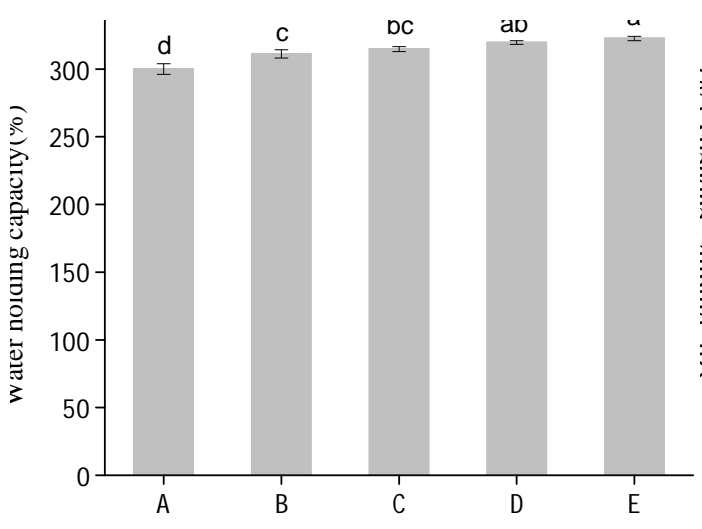

(a)

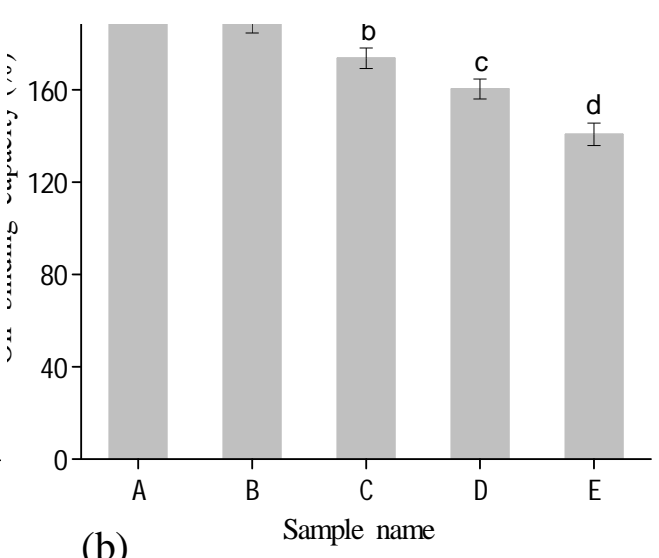

(b)

Fig. 3. WHC (a), OBC (b) of different size of Eucommia ulmoides leaf powders. Different letters in the same column is significantly different $(\mathrm{p}<0.05)$.

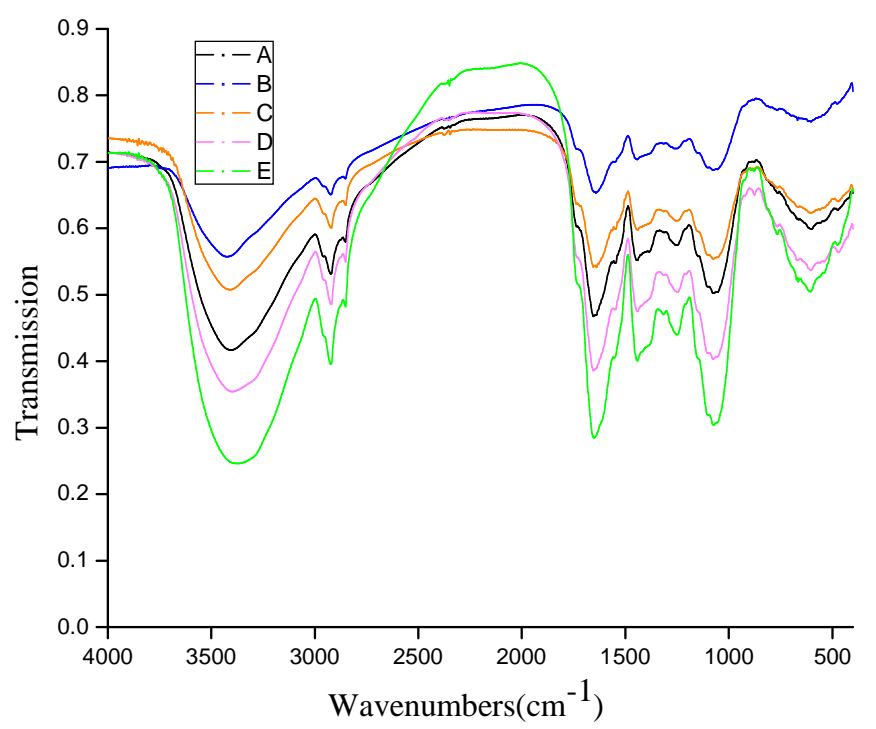

Fig. 4. FT-IR of Eucommia ulmoides leaf powders. Spectrum of Eucommia ulmoides leaves powders with different size.

higher $\mathrm{OBC}$. High $\mathrm{OBC}$ could improve the gastrointestinal cleaning capacity, at the same time, OBC played an important role in weight loss and lowering of cholesterol. Therefore, E. ulmoides leaf superfine powder would be suitable for obese people, but also could be used to decrease the blood lipid level. 
As shown in Table 1, the WSI increased with the particle size of Eucommia ulmoides leaf powders decreased. The WSI values 1 - 5 ranged from 21.12 to $28.19 \%$, WHC of different powder particles samples has significant differences $(\mathrm{p}<0.05)$. A similar result was reported for mulberry leaf powder by Chen et al. (2015). However, the WSI of coarse powders 1 and 4 has not been significantly different but was significantly different compared superfine powder 5 .

The WSI value increased with the decrease of size of E. ulmoides leaves. It could be due to the reduction in average particle size of the superfine powder increased the area/volume ratio, surface energy, and contact area of the powder and solvent, which could led to the increase of solubility of superfine powder.

Furthermore, hydrophilic groups in the cells of E. ulmoides leaves may have been exposed and easily integrated with water, finally leading to increase of the WSI.

The FT-IR spectrum of E. ulmoides leaf powders is presented in Fig. 4 and FT-IR spectrum index of powder samples is given in Table 2. It can be seen that the general spectral profile of $E$. ulmoides leaf powders 1 - 5 was similar, but some of the characteristic bands changed in absorbance and/or wave number. There was a broad band located at about $3419 / \mathrm{cm}$ which was attributed to O-H stretching, was shifted to lower wavenumber by $3404 / \mathrm{cm}$ in the spectra of powder 4 and 5 . The band around at $2925 / \mathrm{cm}$ was due to $\mathrm{C}-\mathrm{H}$ stretching. The main characteristic peaks, which were the stretching vibrations of $\mathrm{C}-\mathrm{C}$ and $\mathrm{C}-\mathrm{O}$, were around $1643 / \mathrm{cm}$ and $1068 / \mathrm{cm}$. The band around at $1444 / \mathrm{cm}$ and $1253 / \mathrm{cm}$ were assigned to $-\mathrm{CH}_{2}$ - symmetric bending and $\mathrm{C}-\mathrm{O}$ stretching, respectively. The transmission peaks of different sizes were similar, which indicated that the decomposition of E. ulmoides leaves during regular grinding and superfine grinding was insignificant.

Table 2. Major absorption in FT-IR spectra of Eucommia ulmoides leaf powders.

\begin{tabular}{cccccl}
\hline \multicolumn{5}{c}{ Sample name } & Assignment \\
\hline A & B & C & D & E & \\
\hline Frequency $\left(\mathrm{cm}^{-1}\right)$ & & & & & \\
3412 & 3419 & 3419 & 3404 & 3404 & O-H group stretching \\
2920 & 2925 & 2922 & 2925 & 2925 & C-H stretching \\
1643 & 1643 & 1643 & 1660 & 1658 & C=C aromatic skeletal vibration \\
1452 & 1450 & 1444 & 1444 & 1444 & -CH2- symmetric bending \\
1253 & 1253 & 1251 & 1251 & 1251 & C-O stretching \\
1068 & 1068 & 1068 & 1068 & 1066 & C-O stretching \\
605 & 605 & 603 & 600 & 600 & O-H bending \\
\hline
\end{tabular}

Compared to regular grinding, the superfine grinding significantly reduced the particle size of E. ulmoides leaves and changed morphology, which had a significant impact on physical-chemical properties: the water solubility index value, water holding capacity value and oil binding capacity value were significantly improved as the size decrease $(\mathrm{p}<0.05)$. Furthermore, biological microscope revealed the surface morphology of five sample powders. FT-IR results indicated that the decomposition of Eucommia ulmoides leaves during regular grinding and superfine grinding was insignificant. Overall, superfine grinding would be more suitable for the development of functional compounds than native Eucommia ulmoides leaves. 


\section{Acknowledgements}

This work was financially supported by the National Key Research and Development Program (2017YFD060130205) and Henan Key Laboratory of cold chain food quality and safety control.

\section{References}

Chen GJ, Wang LS, Zhang FS, Li CL and Kan JQ 2015. Effect of superfine grinding on physicochemical properties of mulberry leaf powder. Trans. Chin. Soc. Agric. Eng. 31: 307-314.

Chen QM, Fu MR, Yue FL and Cheng YY 2015. Effect of superfine grinding on physicochemical properties, antioxidant activity and phenolic content of red rice (Oryza sativa L.). J. Nutr. Sci. 6: 1277-1284.

Chen TQ, Wu YB, Wu JG, Ma L, Dong ZH and Wu JZ 2014. Efficient extraction technology of antioxidant crude polysaccharides from Ganoderma lucidum (Lingzhi), ultrasonic-circulating extraction integrating with superfine-pulverization. J. Taiwan Inst. Chem. E. 45: 57-62.

Chen Y, Zhang BC, Sun YH, Zhang JG, Sun HJ and Wei ZJ 2015. Physicochemical properties and adsorption of cholesterol by okra (Abelmoschusesculentus) powder. Food Funct. 6: 3728-3736.

Chen XM, Sang XX, Li SH, Zhang SJ and Bai LH 2010. Studies on a chlorogenic acid-producing endophytic fungi isolated from Eucommia ulmoides Oliver. J. Ind. Microbiol. Biotechnol. 37: 447-454.

Choi M, Jung UJ, Kim H, Do G, Jeon S, Kim M and Lee M 2008. Du-zhong (Eucommia ulmoides Oliver) leaf extract mediates hypolipidemic action in hamsters fed a high-fat diet. Am. J. Chin Med. 36: 81-93.

Fujikawa T, Hirata T, Wada A and Kawamura N 2010. Chronic administration of Eucommia leaf stimulates metabolic function of rats across several organs. Br J. Nutr. 104: 1868-1877.

Fujikawa T, Hirata T, Hosoo S and Nakajima K 2012. Asperuloside stimulates metabolic function in rats across several organs under high-fat diet conditions, acting like the major ingredient of Eucommia leaves with anti-obesity activity. J. Nutr. Sci. 1: 1-11.

Hirata T, Kobayashi T, Wada A, Ueda T, Fujikawa T, Miyashita H, Ikeda T, Tsukamoto S and Nohara T 2011. Anti-obesity compounds in green leaves of Eucommia ulmoides. Bioorg. Med. Chem. Lett. 21:1786-1791.

Hosoo S, Koyama M, Kato M, Hirata T, Yamaguchi Y, Yamasaki H, Wada A, Wada K, Nishibe S and Nakamura K 2015. The restorative effects of Eucommia ulmoides Oliver leaf extract on vascular function in spontaneously hypertensiverats. Molecules. 20: 21971-21981.

Hu JH, Chen YQ and Nia DJ 2012. Effect of superfine grinding on quality and antioxidant property of fine green tea powders. LWT - Food Sci. Tech. 45: 8-12.

Ileleji KE and Zhou B 2008. The angle of repose of bulk corn stover particles. Powder Tech. 187: 110-118.

Liang XH, Sun JL, Ma HJ 2016. Effect of superfine grinding on physicochemical properties of apple pomace. J. Chem. Soc. Pak. 38: 192-197.

Lin J, Fan YJ, Mehl C, Zhu JJ, Chen H, Jin LY, Xu JH and Wang HM 2011. Eucommia ulmoides Oliv. antagonizes $\mathrm{H}^{2} \mathrm{O}^{2}$-induced rat osteoblastic MC3T3-E1 apoptosis by inhibiting expressions of caspases 3, 6, 7, and 9*. Zhejiang Univ-Sci. B (Biomed \& Biotechnol). 12: 47-54.

Liu SW, Guo S, Xia XY and Chang XD 2015. Effects of dry-, wet- and freeze- grinding pretreatment methods on the physicochemical properties of maitake mushroom (Grifolafrondosa) superfine powders. Adv. J. Food Sci. Technol. 7: 730-738.

Ming J, Chen L, Hong H and Li JL 2015. Effect of superfine grinding on the physic-chemical, morphological and thermos gravimetric properties of Lentinus edodes mushroom powders. J. Sci. Food Agric. 95: 2431-2437.

Phata C, Lia H, Leea D, Moonb B, Yooc B and Leea C 2015. Characterization of Hericium erinaceum powders prepared by conventional roll milling and jet milling. J. Food Eng. 145, 19-24.

Sugawaa H, Ohnoa R, Shirakawaa J, Nakajimab A, Kanagawab A, Hiratac T, Ikedad T, Moroishia N, Nagaia M and Nagai R 2016. Eucommia ulmoides extracts prevent the formation of advanced glycation end products. Food Funct. 7: 2566-2573. 
Sun CC, Liu R, Ni K, Wu T, Luo XY, Liang B and Zhang M 2016. Reduction of particle size based on superfine grinding: Effects on structure, rheological and gelling properties of whey protein concentrate. J. Food Eng. 186: 69-76.

Vladi'c J, Ambrus R, Szabó-Révész P, Vasić A, Cvejin A, Pavlić B and Vidović S 2016. Recycling of filter tea industry by-products: Production of A. millefolium powder using spray drying technique. Ind. Crop Prod. 80: 197-206.

Xiao WH, Zhang Y, Fan CX and Han LJ 2017. A method for producing superfine black tea powder with enhanced infusion and dispersion property. Food Chem. 214: 242-247.

Xu ZS, Tang MT, Li Y, Liu FF, Li XM and Dai RT 2010. Antioxidant properties of Du-zhong (Eucommia ulmoides Oliv.) extracts and their effects on color stability and lipid oxidation of raw pork patties. J. Agric. Food Chem. 58: 7289-7296.

Zhang Q, Su YQ, Yang FX, Peng JN, Li X and Sun YC 2007. Antioxidative activity of water extracts from leaf, male flower, raw cortex and fruit of Eucommia ulmoides Oliv. Forest. Prod. J. 57: 74-78.

Zhang Q, Su YQ and Zhang JF 2013. Seasonal difference in antioxidant capacity and active compounds contents of Eucommia ulmoides Oliver Leaf. Molecules. 18: 1857-1868.

Zhang M, Wang F, Liu R, Tang XL, Zhang Q and Zhang ZS 2014. Effects of superfine grinding on physicochemical and antioxidant properties of Lyciumbarbarum polysaccharides. LWT - Food Sci. Technol. 58: 594-601.

Zhao XY, Yang ZB, Gai GS and Yang YF 2009. Effect of superfine grinding on properties of ginger powder. J. Food Eng. 91: 217-222.

Zhao XY, Ao Q, Du FL, Zhu JQ and Liu J 2010. Surface characterization of ginger powder examined by $\mathrm{X}$-ray photoelectr on spectroscopy and scanning electron microscopy. Colloid Surface. B. 79: 494-500.

Zhao XY, Du FL, Zhu QJ, Qiu DJ, Yin WJ and Ao Q 2010. Effect of superfine pulverization on properties of Astragalus membranaceus powder. Powder Technol. 203: 620-625.

Zhao XY, Chen J, Chen FL, Wang XC, Zhu QJ and Ao Q 2013. Surface characterization of corn stalk superfine powder studied by FTIR and XRD. Colloid Surface. B. 104: 207-212.

Zhao XY, Zhui HT, Chen J and Ao Q 2015. FTIR, XRD and SEM analysis of ginger powders with different size. J. Food Process. Pres. 39: 1745-4549.

Zhong C, Zu YG, Zhao XH, Li Y, Ge WW, Zhang Y, Li YY and Guo DJ 2016. Effect of superfine grinding on physicochemical and antioxidant properties of pomegranate peel. Int. J. Food Sci. Tech. 51: 212-221.

Zhu FM, Du B and Xu BJ 2015. Superfine grinding improves functional properties and antioxidant capacities of bran dietary fibre from Qingke (hull-less barley) grown in Qinghai-Tibet Plateau, China. J. Cereal. Sci. 65: 43-47.

(Manuscript received on 22 March, 2019; revised on 31 March, 2020) 